\title{
Rampf und Kuka intensivieren Zusammenarbeit
}

$R_{d a}^{a n d}$ ampf Dosiertechnik ist zum offiziellen Systempartner der Kuka Roboter GmbH ernannt worden. Damit soll dem Trend Rechnung getragen werden, dass die Bedeutung von Robotiklösungen im Bereich Dosieranlagen weiter stark zunimmt.

Dazu Bernd Faller, Geschäftsführer Rampf Dosiertechnik GmbH \& Co. KG:„Wir können bereits auf eine fruchtbare $\mathrm{Zu}$ sammenarbeit mit der Kuka Roboter GmbH zurückblicken und freuen uns, diese nun weiter zu intensivieren.“

Mit einer platzsparenden Roboter-Dosierzelle, in die der neueste Kuka-Roboter aus dem Bereich Kleinrobotik integriert ist, konnte bereits eine Automatisierungslösung entwickelt werden, deren Einsatz sich überall dort empfiehlt, wo eine hohe Varianz in der Produktion fordert ist.

\section{BASF wehrt sich gegen Patentrechtsverletzungen}

$\mathrm{B}_{\mathrm{n}}^{\mathrm{s}}$ ASF unternimmt entschiedene Schritte, um den Vertrieb nachgeahmter Photoinitiatoren zu stoppen. Händler, die nachgeahmte Produkte der Marke Irgacure 819 nachweislich anbieten, wurden anwaltlich dazu aufgefordert, Vermarktung und Vertrieb der Produkte einzustellen. Ein Händler hat sich bereits dazu verpflichtet, das Produkt mit sofortiger Wirkung vom Markt zu nehmen.

Bei Irgacure 819 handelt es sich um einen weit verbreiteten Photoinitator, der unter UV-Licht chemische Reaktionen auslöst, die den Aushärtungsprozess bei Lacken, Druckfarben und Klebstoffen beschleunigen. Der für die Herstellung des Produktes notwendige Syntheseprozess ist aktuell durch verschiedene Patente geschützt, um andere Unternehmen davon abzuhalten, Irgacure 819 und bestimmte Produktformulierungen - etwa wässrige Suspensionen und Kombinationen mit anderen Photoinitiatoren - herzustellen.

Nach einer intensiven chemischen Analyse kann BASF beweisen, dass die nachgeahmten Produkte unter Verwendung ihres patentierten Syntheseprozesses hergestellt wurden. Laut BASF werden alle Nachahmerprodukte in China produziert und über Händler global verkauft. „Wir gehen davon aus, dass alle betroffenen Händler unsere Patentrechte akzeptieren werden, so dass keine Gerichtsverfahren notwendig sein dürften”, sagte Ralf Spettmann, der das europäische Pigment- und Harzgeschäft der BASF leitet. „Die Achtung von Patentrechten ist für uns von großer Bedeutung, um unser geistiges Eigentum zu schützen und Innovationen in den Bereichen Forschung und Entwicklung voranzutreiben.“
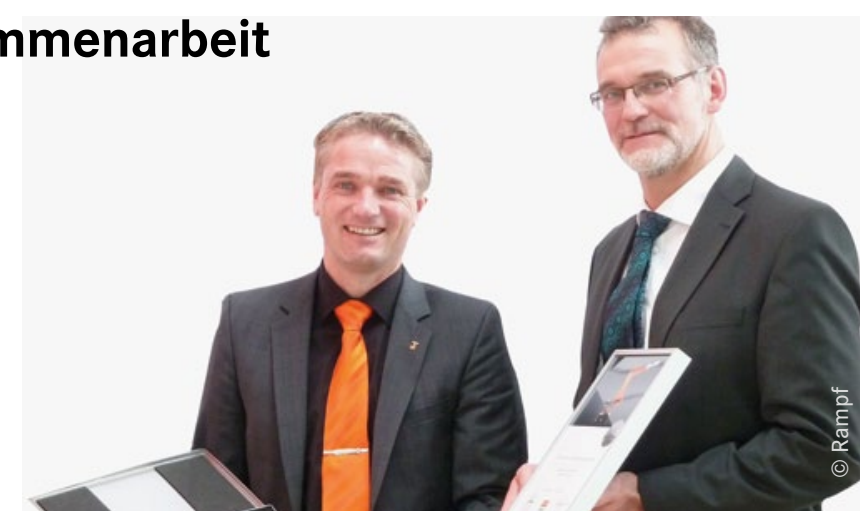

Die bisherige Zusammenarbeit soll weiter intensiviert werden: Bernd Faller, Geschäftsführer von Rampf Dosiertechnik (rechts), nimmt die Ernennungsurkunde zum Kuka-Systempartner von Bernd Besserer, Gebietsbetreuer Süd bei Kuka Roboter $\mathrm{GmbH}$, entgegen.

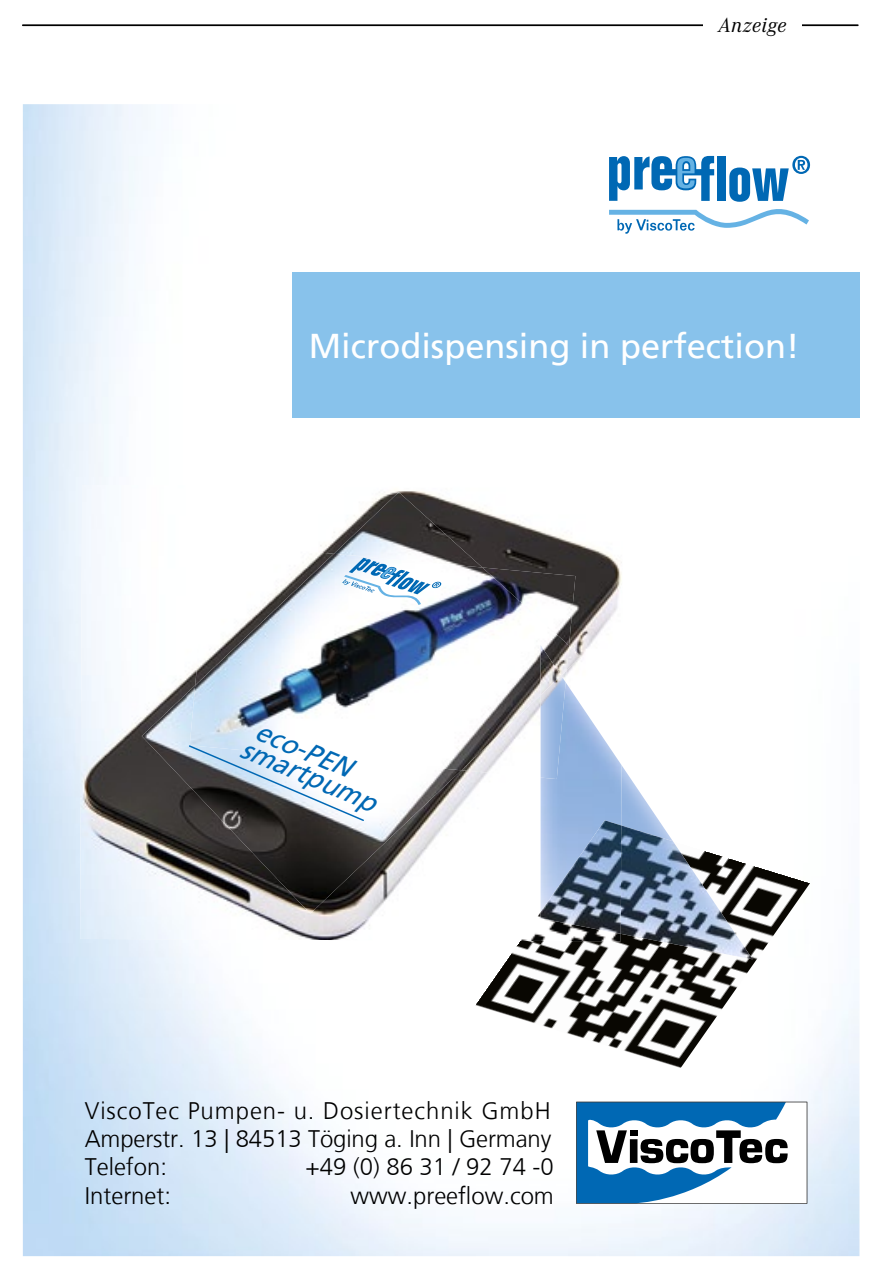

